\title{
Perilaku Petani Padi Sawah Dalam Menggunakan Pestisida Kimia di Kecamatan Harau, Kabupaten Lima Puluh Kota, Sumatera Barat, Indonesia
}

\author{
(Behavior of Paddy Farmers Using Chemical Pesticides in Harau District, Lima \\ Puluh Kota Regency, West Sumatera, Indonesia)
}

\author{
Helentina Situmorang", Noveri, Mispit Putrina, Elva Rahmi Fitri \\ Program Studi Budidaya Tanaman Perkebunan, Politeknik Pertanian Negeri Payakumbuh \\ `Email korespondensi: situmorang.helentina@gmail.com
}

\begin{abstract}
One of the centers of lowland rice production in Indonesia is West Sumatra Province in Harau District. The total production of lowland rice in Harau sub-district was 45,784 tons in 2018 with a planting area of 11,266 ha. However, the problems faced in rice cultivation activities in Harau District are several pests that often attack rice plants, including golden snails, rats, walang sangit, ground bed bugs, leafhoppers, and birds. Therefore, most paddy rice farmers control pests by using chemical pesticides. In fact, the continuous use of chemical pesticides causes the ecosystem around the land to be damaged. The purpose of this study was to determine the behavior of rice farmers in using chemical pesticides in Harau District, Lima Puluh Kota Regency. The research was conducted in June-October 2020 in Nagari Sarilamak and Nagari Gurun, Harau District. The method used is a survey with a purposive sampling of 30 respondents. Analysis of the data used in this research is descriptive based on perceptions, motives and attitudes of farmers in the use of chemical pesticides. The results showed that according to the farmer's perception, it was absolutely necessary to control the use of chemical pesticides and reduce the risk of decreased rice production/harvest failure; farmers' motives for using chemical pesticides that are well known, proven to be effective and easy to find in markets/kiosks, but not based on an understanding of the active substances contained in these pesticides; and the attitude of farmers who are willing to pay a high price for pesticides that are proven to be effective in controlling lowland rice pests. Farmers are more concerned with the risk of crop failure than the adverse effects of chemical pesticides on the environment. Suggestions for further research on pesticide levels in lowland rice products and the impact of using chemical pesticides on the environment.
\end{abstract}

Keywords: behavior of paddy farmers; chemical pesticides; environment; paddy rice.

\begin{abstract}
Abstrak. Salah satu sentra produksi padi sawah di Indonesia adalah Provinsi Sumatera Barat di Kecamatan Harau. Jumlah produksi padi sawah di kecamatan Harau sebesar 45.784 ton tahun 2018 dengan luas tanam 11.266 ha. Namun, permasalahan yang dihadapi dalam kegiatan budidaya tanaman padi di Kecamatan Harau adalah beberapa hama yang sering menyerang tanaman padi antara lain keong emas, tikus, walang sangit, kepinding tanah, wereng, dan burung. Oleh sebab itu sebagian besar petani padi sawah melakukan pengendalian hama dengan menggunakan pestisida kimia. Padahal, penggunaan pestisida kimia secara terus menerus mengakibatkan ekosistem di sekitar lahan menjadi rusak. Tujuan penelitian ini adalah untuk mengetahui perilaku petani padi sawah dalam menggunakan pestisida kimia di Kecamatan Harau Kabupaten Lima Puluh Kota. Penelitian dilaksanakan pada bulan Juni-Oktober 2020 di Nagari Sarilamak dan Nagari Gurun Kecamatan Harau. Metode yang digunakan adalah survei dengan pengambilan sampel secara sengaja (purposive sampling) sebanyak 30 responden. Analisis data yang digunakan dalam penelitian ini adalah secara deskriptif berdasarkan persepsi, motif dan sikap petani dalam penggunaan pestisida kimia. Hasil penelitian diperoleh bahwa menurut persepsi petani mutlak melakukan pengendalian dengan penggunaan pestisida kimia dan mengurangi resiko produksi padi menurun/gagal panen; motif petani penggunaan pestisida kimia yang sudah terkenal, terbukti ampuh dan mudah ditemukan di pasar/kios, tetapi tidak berdasarkan pemahaman atas zat aktif yang terkandung dalam pestisida tersebut; dan sikap petani bersedia membayar mahal pestisida yang terbukti ampuh mengendalikan hama padi sawah.. Petani lebih mempertimbangkan resiko kegagalan panen dibandingkan dampak buruk pestisida kimia terhadap lingkungan.

Kata kunci: lingkungan; padi sawah; perilaku petani; pestisida kimia
\end{abstract}

\section{PENDAHULUAN}

Tanaman padi merupakan tanaman budidaya yang sangat penting bagi masyarakat Indonesia. Mayoritas masyarakat Indonesia mengonsumsi padi sebagai alat untuk memenuhi kebutuhan pangan. Menurut Utama (2015), pengelompokan padi berdasarkan lingkungan tempat tumbuhnya terdiri dari padi rawa, padi sawah, dan padi lahan kering (gogo). Pada umumnya tingkat produksi padi sawah jauh lebih tinggi 
dibandingkan dengan kedua kelompok lainnya. Hal ini terjadi karena pola budidaya pada lahan sawah sudah sangat intensif dan penerapan teknologi budidaya seperti penggunaan varietas unggul. Salah satu sentra produksi padi sawah di Indonesia adalah Provinsi Sumatera Barat di Kecamatan Harau. Tabel 1 menunjukkan jumlah produksi pangan yang terbesar di Kecamatan Harau adalah padi sawah sebesar 45.784 ton tahun 2018 dengan luas tanam 11.266 ha. Produksi padi sawah mengalami peningkatan dibandingkan tahun 2017 sebesar 27,03\% dengan penambahan luas tanam sebesar 22,71\% (BPS, 2019).

Tabel 1. Luas tanam produksi tanaman pangan di Kecamatan Harau tahun 2017-2018

\begin{tabular}{llllll}
\hline \multirow{2}{*}{ No } & \multirow{2}{*}{ Jenis Tanaman } & \multicolumn{2}{l}{ Luas Tanam (ha) } & \multicolumn{2}{l}{ Produksi (ton) } \\
\cline { 3 - 6 } & & 2017 & 2018 & 2017 & 2018 \\
\hline 1 & Padi sawah & 8.707 & 11.266 & $33.407,21$ & 45.784 \\
\hline 2 & Jagung & 714 & 1.115 & 3.773 & 4.777 \\
\hline 3 & Ubi kayu & 110 & 124 & $6.594,14$ & 913,40 \\
\hline
\end{tabular}

Sumber: (BPS, 2019)

Permasalahan yang dihadapi dalam kegiatan budidaya tanaman padi semakin beragam seperti perubahan iklim global yang berdampak terhadap anomali iklim mendorong perkembangan hama dan penyakit yang mengancam keselamatan pertumbuhan tanaman padi. Akibatnya, keuntungan usahatani menurun karena harus dikurangi dengan biaya pengendalian hama penyakit yang semakin tinggi dan kualitas produksi pun menurun sehingga kalah bersaing di pasar (Nuryanto, 2018).

Terdapat puluhan ribu penyakit yang dapat mengganggu pertumbuhan tanaman budidaya. Serangan penyakit pada tanaman akan menyebabkan terjadinya kerusakan pada sel atau jaringan, sehingga tumbuhan yang sakit menjadi sangat lemah, bahkan dapat mengalami kematian karena serangan dari penyakit tersebut. Penyebab penyakit tanaman padi terdiri dari golongan biotik dan abiotik. Golongan biotik seperti penyakit blast (Pyricularia), bercak coklat (brown spot), hawar upih daun (sheath blight), hawar Fusarium, kerdil rumput (grassy stunt) dan kerdil hampa (ragged stunt). Golongan abiotik seperti kekeringan, suhu ekstrim, keasaman tanah, kekurangan unsur hara, kelebihan air, polusi udara, angin, dan limbah industri yang berbahaya (Nuryanto, 2018). Hama yang sering menyerang tanaman padi adalah keong mas, kepinding tanah, tikus dan wereng sehingga menyebabkan kerugian yang tidak kecil bagi petani. Menurut Makarim (2000) dalam Ifgayani dkk (2019) bahwa salah satu penyebab belum optimalnya produktivitas padi sawah antara lain disebabkan belum efektifnya pengendalian hama penyakit. Oleh sebab itu sebagian besar petani padi sawah di Kecamatan Harau mengatasi resiko kegagalan panen akibat serangan hama dan penyakit dengan menggunakan pestisida kimia, fungisida dan insektisida. Penggunaan pestisida kimia secara terus menerus mengakibatkan ekosistem di sekitar lahan menjadi rusak. Kartasapoetra (1994), menyatakan setiap petani ingin meningkatkan kesejahteraan hidupnya, sehingga petani tidak ingin serangan hama menurunkan produktivitas padi dan berpengaruh terhadap pendapatan dan kesejahteraan petani padi sawah.

Penelitian tentang perilaku petani telah banyak dilakukan. Salah satunya penelitian yang dilakukan oleh Puspitasari (2017) bahwa faktor yang membentuk perilaku petani dalam menggunakan pestisida kimia adalah persepsi petani menggunakan pestisida kimia, motif menggunakan jenis pestisida kimia, dan sikap petani dalam menggunakan pestisida kimia. Dari penelitian Yulisal (2018) di Kota Solok Sumatera Barat, didapat hasil bahwa perilaku petani dalam penggunaan pestisida kimia pada tanaman padi dipengaruhi oleh 
pengetahuan, sikap dan tindakan petani, dimana semua petani menggunakan pestisida kimia untuk mengendalikan hama dan penyakit. Lebih lanjut Yulisal (2018) mengatakan bahwa secara umum pengetahuan petani dalam aplikasi pestisida kimia buatan sudah cukup baik, tetapi masih terdapat petani yang mengambil tindakan dalam aplikasi pestisida yang belum sesuai dengan pengetahuan dan sikapnya. Aplikasi pestisida yang tidak tepat dapat dipengaruhi oleh tingkat pendidikan, pengalaman bertani, serta kepatuhan terhadap rekomendasi dan informasi yang terdapat pada label pestisida.

Indikator persepsi petani terhadap penggunaan pestisida kimia adalah penggunaan pestisida kimia mutlak untuk usahatani atau penggunaan pestisida akan meningkatkan produktivitas. Indikator motif menggunakan jenis pestisida kimia adalah paham atas zat aktif yang terkandung, sudah terkenal, terbukti ampuh, direkomendasikan petani lain, mudah ditemukan di pasar, adanya diskon, adanya promosi yang gencar. Indikator sikap petani memilih jenis pestisida kimia adalah selalu memilih pestisida yang harganya murah, bersedia membayar mahal untuk pestisida kimia yang ampuh, selalu mencoba-coba berbagai macam pestisida kimia, menggunakan pestisida kimia karena mengikuti petani lain (Puspitasari, 2017).

Resiko kegagalan panen pada tanaman padi sawah akibat hama sangat tinggi. Petani tidak bisa mengendalikan hama dengan cepat jika menggunakan pengendalian secara hayati atau pengendalian secara terpadu. Petani lebih mempertimbangkan resiko kegagalan panen dibandingkan dampak buruk pestisida kimia terhadap lingkungan dan salah satu faktor yang mempengaruhi produksi padi sawah adalah pestisida (Suharyanto,et.al., 2015). Resiko kegagalan panen dan produksi panen menurun dihadapi petani padi sawah apabila serangan hama tidak segera dikendalikan. Menurut petani bahwa cara pengendalian hama yang cepat dan efektif dengan menggunakan pestisida kimia Maka, penelitian ini bertujuan untuk mengetahui perilaku petani padi sawah dalam penggunaan pestisida kimia di Kecamatan Harau Kabupaten Lima Puluh Kota Sumatera Barat.

\section{METODE}

Penelitian dilaksanakan pada bulan JuniOktober 2020 di Nagari Sarilamak dan Nagari Gurun Kecamatan Harau Kabupaten Lima Puluh Kota Sumatera Barat. Metode yang digunakan survei dengan wawancara petani dan pengambilan responden secara purposive berdasarkan pekerjaan utama berusahatani padi sawah sebanyak 15 responden di Nagari Sarilamak dan 15 responden di Nagari Gurun.

Data yang diperoleh adalah data primer dan sekunder. Data primer diperoleh dari wawancara dengan menggunakan kuesioner, sedangkan data sekunder diperoleh dari instansi terkait dengan informasi mengenai pengendalian hama dan penyakit padi sawah Analisis data yang digunakan dalam penelitian ini adalah secara deskriptif bagaimana perilaku petani padi sawah menggunakan pestisida kimia berdasarkan persepsi, motif, dan sikap, petani dalam penggunaan pestisida kimia di Kecamatan Harau.

\section{HASIL DAN PEMBAHASAN}

\section{Pengendalian Hama Padi Sawah di Kecamatan Harau}

Hasil penelitian memperlihatkan bahwa padi sawah di Kecamatan Harau terserang hama keong mas, burung, walang sangit, penggerek batang, kepinding tanah dan wereng. Petani melakukan pengendalian hama sebagian besar $(96,67 \%$ atau 29 orang petani responden) dengan menggunakan pestisida kimia. 1 orang petani responden tidak menggunakan pestisida kimia. Pengendalian keong mas dengan menggunakan abozole. Pengendalian walang sangit menggunakan pestisida Curater, Sakil dan Decis. Pengendalian hama penggerek batang menggunakan pestisida Curacron dan pengendalian hama wereng menggunakan pestisida Alika. Padi sawah di Kecamatan 
harau paling banyak diserang oleh hama walang sangit, penggerek batang, kepinding tanah dan wereng. Jika tidak dilakukan pengendalian maka kemungkinan besar terjadi gagal panen. Menurut Sastroutomo (1992), sebagai usaha untuk menjamin produksi pertanian yang cukup maka manusia menggunakan berbagai cara dan usaha untuk mengendalikan hama dan penyakit yang menyerang tanaman. Salah satu diantaranya adalah pengendalian secara kimiawi dengan menggunakan pestisida, dimana penggunaan pestisida telah berhasil menyelamatkan produksi pertanian yang dihancurkan oleh hama dan penyakit.

Petani melakukan pengendalian hama burung secara mekanis yaitu dengan menggunakan jaring dan pengendalian tikus dengan menggunakan belerang. Pengendalian hama burung masih bisa dikendalikan dengan mekanis, karena tingkat serangan hama burung tidak sebanyak serangan hama walang sangit, penggerek batang, kepinding tanah dan wereng. Menurut Oka (1998), konsep PHT (Pengendalian Hama Terpadu) menekankan penggunaan pestisida yang rasional, bila perlu saja, berdasarkan apabila tingkat kerusakan sudah merugikan secara ekonomi. Hasil penelitian Listiana (2017) bahwa kapasitas petani dalam menerapkan teknologi PHT padi sawah sebagian besar dalam klasifikasi rendah.

\section{Perilaku Petani Padi Sawah Menggunakan Pestisida Kimia Di Kecamatan Harau}

Berdasarkan hasil wawancara dengan petani responden bahwa perilaku petani padi sawah menggunakan pestisida kimia adalah persepsi, motif, sikap petani, pengetahuan, dan pengalaman petani di Kecamatan Harau. Persepsi petani menggunakan pestisida kimia

Pada tabel 2 diperoleh persepsi petani menyatakan bahwa ketika padi mengalami serangan hama, maka petani sebanyak 29 orang $(96,67 \%)$ mutlak melakukan pengendalian dengan penggunaan pestisida kimia, karena mereka berkeyakinan akan meningkatkan produktivitas padi sawah. Hal ini sesuai hasil penelitian Eliza dkk (2013) bahwa penggunaan pestisida kimia dilakukan petani secara terjadwal tanpa melihat ada atau tidaknya serangan hama dan penyakit. Sedangkan 1 orang petani $(3,33 \%)$ tidak melakukan pestisida kimia, alasan petani karena padi sawah petani tersebut tidak mengalami serangan hama yang banyak.

Tabel 2. Persepsi petani terhadap penggunaan pestisida kimia

\begin{tabular}{lcccccc}
\hline $\begin{array}{l}\text { Persepsi petani terhadap penggunaan } \\
\text { pestisida kimia }\end{array}$ & $\begin{array}{l}\text { Sangat } \\
\text { setuju }\end{array}$ & $\begin{array}{l}\text { tidak } \\
\text { setuju }\end{array}$ & $\begin{array}{c}\text { Agak } \\
\text { setuju }\end{array}$ & Setuju & $\begin{array}{l}\text { Sangat } \\
\text { setuju }\end{array}$ \\
\hline $\begin{array}{l}\text { Penggunaan pestisida kimia mutlak pada } \\
\text { usahatani padi sawah }\end{array}$ & $0 \%$ & $3,33 \%$ & $0 \%$ & $96,67 \%$ & $0 \%$ \\
\hline $\begin{array}{l}\text { Penggunaan pestisida mengurangi resiko } \\
\text { produksi padi tidak menurun/gagal panen }\end{array}$ & 0 & 1 & 0 & 29 & 0 \\
\hline
\end{tabular}

Sumber: Data diolah (2020)

Petani memiliki persepsi juga bahwa penggunaan pestisida kimia dapat mengurangi penurunan produksi padi sawah dan resiko gagal panen $(96,67 \%$ atau 29 orang petani responden). Hal ini sesuai hasil penelitian Puspitasari, (2017), bahwa petani meminimalisir resiko kegagalan panen, bahkan sebelum diserang hama, petani sudah menggunakan pestisida kimia. Hal ini sesuai juga hasil penelitian Yulisal, (2018), menyatakan bahwa petani tetap memilih menggunakan pestisida kimia untuk mengendalikan hama dan penyakit agar produksi tidak turun. Namun, petani tidak mempertimbangkan akan bahaya menggunakan pestisida secara kimia secara terus menerus. Hasil penelitian Yuantari dkk (2013) bahwa tingkat pengetahuan tentang penggunaan pestisida kimia dan bahayanya masih kurang. Misalnya dampak negatif pada tanah, air, manusia dan lingkungan sekitar sawah. Seperti masih banyak petani yang 
mencuci alat semprot di sungai atau parit (Satyani dkk, 2017).

\section{Motif petani menggunakan pestisida kimia}

Pada tabel 3 menunjukkan motif petani menggunakan pestisida kimia sebanyak 29 orang (100\%), karena pestisida kimia tersebut sudah terkenal, terbukti ampuh, direkomendasikan petani lain dan mudah ditemukan di pasar/kios. Sedangkan, petani tersebut (sebanyak 29 orang) tidak memahami atas zat aktif yang terkandung kimia tersebut.

Tabel 3. Motif Petani terhadap Penggunaan Pestisida Kimia

\begin{tabular}{|c|c|c|c|c|c|}
\hline Alasan menggunakan pestisida tertentu & $\begin{array}{l}\text { Sangat tidak } \\
\text { setuju }\end{array}$ & Tidak setuju & Agak setuju & Setuju & Sangat setuju \\
\hline \multirow{2}{*}{ Paham atas zat aktif yang terkandung } & 0 & 29 & 0 & 0 & 0 \\
\hline & $0 \%$ & $100 \%$ & $0 \%$ & $0 \%$ & $0 \%$ \\
\hline \multirow{2}{*}{ Sudah terkenal } & 0 & 0 & 0 & 14 & 15 \\
\hline & $0 \%$ & $0 \%$ & $0 \%$ & $48,27 \%$ & $51,72 \%$ \\
\hline \multirow{2}{*}{ Terbukti ampuh } & 0 & 0 & 0 & 0 & 29 \\
\hline & $0 \%$ & $0 \%$ & $0 \%$ & $0 \%$ & $100 \%$ \\
\hline \multirow{2}{*}{ Direkomendasikan petani lain } & 0 & 0 & 0 & 25 & 4 \\
\hline & $0 \%$ & $0 \%$ & $0 \%$ & $86,20 \%$ & $13,79 \%$ \\
\hline \multirow{2}{*}{ Mudah ditemukan di pasar/kios } & 0 & 0 & 0 & & 29 \\
\hline & $0 \%$ & $0 \%$ & $0 \%$ & $0 \%$ & $100 \%$ \\
\hline
\end{tabular}

Sumber: Data diolah (2020)

\section{Sikap petani menggunakan pestisida kimia}

Sikap petani dalam menggunakan pestisida kimia adalah petani bersedia membayar harga mahal untuk pestisida kimia yang ampuh mengendalikan hama padi sawah, sehingga sesama petani akan bertukar informasi tentang pengalaman keefektifan penggunaan pestisida kimia supaya tidak terjadi gagal panen.

Karena itu, petani menyatakan bahwa petani tidak memiliki pilihan jika tidak menggunakan pestisida kimia untuk mengantisipasi kegagalan panen. Walaupun
1 orang petani responden mengendalikan hama dengan mekanis karena padi petani tersebut tidak mengalami serangan hama yang banyak sehingga masih bisa dikendalikan secara mekanis. Namun, hasil penelitian Tahyudin dkk, (2020), menyatakan perilaku petani dalam mereduksi penggunaan pestisida kimia mayoritas pada kategori sedang dengan persentase $81 \%$ dengan strategi menyelenggarakan penyuluhan, membuat petak percontohan penerapan teknologi PHT (Pengendalian Hama Terpadu), dan mengadakan temu lapang pengenalan teknologi PHT.

Tabel 4. Sikap petani menggunakan pestisida kimia

\begin{tabular}{llllll}
\hline Sikap petani & $\begin{array}{l}\text { Sangat } \\
\text { tidak setuju }\end{array}$ & $\begin{array}{l}\text { Tidak } \\
\text { setuju }\end{array}$ & $\begin{array}{l}\text { Agak } \\
\text { setuju }\end{array}$ & Setuju & $\begin{array}{l}\text { Sangat } \\
\text { setuju }\end{array}$ \\
\hline $\begin{array}{l}\text { Selalu memilih pestisida yang } \\
\text { harganya murah }\end{array}$ & 4 & 25 & 0 & 0 & 0 \\
\hline $\begin{array}{llllll}\text { Bersedia membayar mahal untuk } \\
\text { pestisida yang ampuh }\end{array}$ & 0 & 0 & $0 \%$ & $0 \%$ & $0 \%$ \\
\cline { 2 - 7 } $\begin{array}{l}\text { Selalu mencoba-coba berbagai } \\
\text { macam pestisida }\end{array}$ & $0 \%$ & $0 \%$ & $0 \%$ & $72,41 \%$ & $27,59 \%$ \\
\cline { 2 - 7 } & $0 \%$ & $0 \%$ & $0 \%$ & $100 \%$ & $0 \%$ \\
\hline $\begin{array}{l}\text { Menggunakan pestisida karena } \\
\text { mengikuti petani lain }\end{array}$ & 0 & 0 & 0 & 25 & 4 \\
\hline
\end{tabular}

Sumber: Data diolah (2020) 
Hal ini didukung hasil penelitian A'Yunin dkk, (2020), bahwa preferensi anggota kelompok tani di Kelurahan Purwaharja untuk meminimalisir penggunaan pestisida kimia pada tanaman padi sawah kategori tinggi $(74,28 \%)$ dan kategori sedang $(25,71 \%)$ dengan adanya peran penyuluh melalui demonstrasi membuat petak percontohan.

\section{SIMPULAN}

Berdasarkan hasil penelitian, maka dapat disimpulkan bahwa (1) petani melakukan pengendalian hama sebagian besar secara kimia, (2) perilaku petani dalam penggunaan pestisida kimia adalah menurut persepsi petani mutlak melakukan pengendalian dengan penggunaan pestisida kimia dan mengurangi risiko produksi padi menurun/gagal panen; motif petani penggunaan pestisida kimia yang sudah terkenal, terbukti ampuh dan mudah ditemukan di pasar/kios, tetapi tidak berdasarkan pemahaman atas zat aktif yang terkandung dalam pestisida tersebut; dan sikap petani bersedia membayar mahal pestisida yang terbukti ampuh mengendalikan hama padi sawah. Petani lebih mempertimbangkan resiko kegagalan panen dibandingkan dampak buruk pestisida kimia terhadap lingkungan

\section{UCAPAN TERIMA KASIH}

Tim penulis mengucapkan terimakasih kepada petani padi sawah di Kecamatan Harau atas kesediaan memberikan informasi yang dibutuhkan dalam penelitian. Ucapan terima kasih juga buat Politeknik Pertanian Negeri Payakumbuh yang membantu dana penelitian.

\section{DAFTAR PUSTAKA}

A'Yunin, Nidia Qurrota, Achdiyat, T. R. S. (2020). Preferensi Anggota Kelompok Tani Terhadap Penerapan Prinsip Enam Tepat (6T) Dalam Aplikasi Pestisida. Jurnal Inovasi Penelitian, 1(3), 253264.
BPS. (2019). Kecamatan Harau Dalam Angka.

Eliza, Try, Tubagus Hasanuddin, S. S. (2013). Perilaku Petani Dalam Penggunaan Pestisida Kimia (Kasus Petani Cabai di Pekon Gisting Atas Kecamatan Gisting Kabupaten Tanggamus. JIIA, 1(4), 334-342.

Ifgayani, Tri , Made Antara, L. D. (2019). Analisis Faktor-Faktor Yang Memengaruhi Produksi Padi Sawah Di Desa Uetoli Kecamatan Ampana Tete Kabupaten Tojo Una-Una. Agroland, 26(2), 111-122.

Kartasapoetra, A. G. (1994). BA.01.45.0063 (1st ed.). Bumi Aksara.

Listiana, I. (2017). Kapasitas Petani dalam Penerapan Teknologi Pengendalian Hama Terpadu (PHT) Padi Sawah di Kelurahan Situgede Kota Bogor. Agrica Ekstensia, Vol. 11(1), 46-52.

Nuryanto, B. (2018). Pengendalian Penyakit Tanaman Padi Berwawasan Lingkungan Melalui Pengelolaan Komponen Epidemik. Jurnal Penelitian Dan Pengembangan Pertanian, 37(1), $1-8$.

https://doi.org/10.21082/jp3.v37n1.201 8.p1-8.

Oka, I. N. (1998). Pengendalian Hama Terpadu dan Implementasinya Di Indonesia. Gajah Mada University Press.

Puspitasari, A. M. K. (2017). Perilaku Petani Dalam Menggunakan Pestisida Di Sentra Produksi Bawang Merah Kabupaten Brebes. 786-795.

Sastraoutomo, S. S. (1992). Pestisida, Dasar-Dasar Dan Dampak Penggunaannya. PT. Gramedia Pustaka Utama.

Satyani, Tri , Arfan, S. (2017). Evaluasi Penggunaan Pestisida Pada Petani Bawang Merah Di Desa Wombo Mpanau Kecamatan Tanantovea Kabupaten Donggala. Agrotech, 9(1), 26-32.

Suharyanto, Jangkung H.Mulyo, D. H. D. dan S. W. (2015). Analisis Produksi dan 
Efisiensi Pengelolaan Tanaman Terpadu Padi Sawah di Provinsi Bali. Penelitian Pertanian Tanaman Pangan, 34(2), 131-143.

Tahyudin, Rudi Hartono, O. A. (2020). Perilaku Petani Dalam Mereduksi Penggunaan Pestisida Kimia Pada Budidaya Bawang Merah. Jurnal Kommunity Online, 1(1), 21-30.

Utama, Z. H. (2015). Budidaya padi pada lahan marjinal. (1st ed.). Andi.

Yuantari, MG Catur, Budi Widiarnako, H. R.
S. (2013). Tingkat Pengetahuan Petani dalam Menggunakan Pestisida (Studi Kasus di Desa Curut Kecamatan Penawangan Kabupaten Grobogan). Seminar Nasional Pengelolaan Sumberdaya Alam Dan Lingkungan 2013, 142-148.

Yulisal, N. W. (2018). Pengetahuan, Sikap, Dan Tindakan Petani Padi Dalam Penggunaan Pestisida Di Kota Solok Sumatera Barat. Institut Pertanian Bogor. 